\title{
EVERYDAY WORK INVESTIGATIONS FOR SAFETY
}

\author{
Authors: Jop HaVINGA, SidNEy DEKKER, AND ANDREW RAE
}

School of Humanities, Griffith University, 170 Kessels Road, Brisbane, 4111, Queensland, Australia

\begin{abstract}
A key theme in safety is the investigation and improvement of work processes and conditions. This is built on a tradition of studying accidents, but there is growing interest in the investigation of everyday work. Researchers have started using terms such as success, normal, and everyday work investigations, but behind these can be different activities. This paper makes explicit some considerations behind investigations of everyday work, how these considerations shape an investigation, and how they reflect different schools of thought. These considerations can be used as an aid for designing everyday work investigations for safety and serve as a first step towards critical reflection on investigating everyday work.
\end{abstract}

Keywords: safety; investigation; methodology; everyday work; resilience engineering Relevance to human factors / ergonomics theory: Improving the conditions of work ergonomic or otherwise - can be enhanced by systematically studying how and why things go well, rather than investigating why they go wrong or fail. Different theoretical approaches inspire how this can be done, from normative to descriptive to formative.

\section{INTRODUCTION}

The safety community is seeing a growing interest in investigating success and normal work, in addition to (or instead of) investigating things that have gone wrong, such as incidents and accidents. What has been called "Safety-II" specifically advocates looking at how success is created, instead of how a particular failure has happened (Hollnagel, 2014). In the study of work itself, this is nothing new of course. Taylor's and Gilbreth's time and motion studies investigated 'normal work', though their concern was productivity, not necessarily safety (even though some of their studies did include a focus on the errors made by the worker) (Taylor 1911). Ergonomics, naturalistic decision making, distributed cognition, cognitive 
work analysis and cognitive systems engineering have since all contributed to the study of everyday work (Hoffman and Militello 2008). In addition, there are many forms of task analysis, some of which only focus on how work should be done, not on how it is actually done (Annett 2000), and safety is not always, or seldom, the main concern. The challenge is in talking about everyday work and safety at the same time.

From a safety perspective, the importance of understanding everyday work relates to the mismatch between how people think work is done - how it is captured in procedures-, and how work is actually done (Hollnagel 2014). This has been called the difference between task and activity (Leplat and Hoc 1983), procedure and practice (Dekker 2003), or indeed work-as-imagined and work-as-done (Hollnagel 2014; Dekker 2005). In more judgmental terms, actual work that doesn't match work as imagined has also been characterised as a workaround or even a violation (Spear and Schmidhofer 2005; Reason 1997; Debono et al. 2013). Where cognitive work takes place 'in the wild,' as Hutchins puts it (1995), pragmatic and highly nuanced adaptations of tools, techniques, and practices is not only extremely common, but generally crucial for the creation of safety at the sharp end. Hollnagel (2012) too, stresses that work-as-imagined can never capture the full complexity, or the 'messy details' (Nemeth, Cook, and Woods 2004) of actual work. This means that addressing the mismatch is not a matter of enforcing closer alignment between actual activities and how work was once imagined to be. Rather, the challenge for an organisation becomes to learn more about how it actually operates mostly successfully and safely at its many "sharp ends" of practice (Woods et al. 2010). For the purposes of this paper, everyday work investigations refer to organised activities to learn how people or organisations operate. This is done to better understand how safety is created and broken in people's everyday activities, particularly in how they respond to goal interactions, local insights and resource limitations.

The historical legacy of safety research and practice has created methods, guides and critical reflections on investigating things that have gone wrong-many more than there are for investigating everyday work. Even though accident and incident investigation techniques might suggest some basis for investigating everyday work, they provide little practical guidance on how to do so. Ergonomic based methods, on the other hand, often come from a background of looking at individuals and an aim for the redesign of technology. While useful, these are not the only relevant factors for safety. One can set out and apply these investigation methods and tweak them until they produce results in the new setting. However, this approach would miss out on more fundamental considerations of the worldviews, goals, and concepts that come with a focus on accidents. This could limit the investigation of everyday work, and be unable to cope with the challenges the come with investigating everyday work. For one, many work-as-done adaptations are integrated into practice so smoothly, subtly and unobtrusively that they are all but invisible to the untrained eye (Cook and Woods 1994). And without the rubble of an accident or incident to start backtracking from, there is no clear trigger point for investigating everyday work.

In addition, everyday work investigations are beset by many of the same problems as incident/accident investigation. The cognitive systems in which everyday work is embedded are complex, deeply intertwined and filled with uncertainties, and investigator observations are inevitably driven by the categorical forestructures that are taken into the field of 
observation. That said, there are distinct advantages of investigating normal work. There are more opportunities to gather data (Hollnagel 2014) and data is not limited to retrospective records and interpretations of an event. Observations can be trained on ongoing work instead. Opportunities thus exist to both generate and verify hypotheses with new data. And of course, without a bad outcome that triggered it, the investigation of normal work should be free from the psychological defense mechanisms (and from at least some of the effects of outcome and hindsight bias) that typically mar the aftermath of an incident or accident (Dekker 2014; Merry and McCall Smith 2001).

Our purpose in this paper is to discuss the theoretical considerations for conducting everyday work investigations related to safety. In particular, we discuss the effect that different research questions and methodological assumptions have on the type of conclusions that can be reached, and the relationships between these conclusions and the ultimate goal of improving workplace safety.

To illustrate our discussion, we use as a running example an empirical study of everyday work by blast crews. It is not our intention to provide a full report of the methods or results of that study here, but to use our experiences in designing and conducting the study to support a broader reflection on what can be investigated and what makes sense to investigate. We also reference other everyday work studies, adopting a range of different approaches. Using these examples, we discuss some considerations to make when investigating everyday work, linked to various safety schools of thought and fields that study work.

\section{BLAST CREWS}

In a mine, the role of the blast crews is to 'soften' up the ground. By using explosives they crush the ground, so that diggers in the mine have an easier job. If their blast is too weak, the rocks afterwards are too big. If their blast is too strong, environmental norms can be exceeded and debris can be flung away from the blast area. Besides debris, the job of blast crews is safety critical due to risk of premature and uncontrolled detonation, and managing risks that come with heavy vehicles.

Before a blast can be done, the area to be blasted is surveyed. After it is surveyed a 'shot' is designed, which means a plan is made to decide what kinds of explosive 'product' is used and how the product will be distributed among the area. According to the design, the holes are drilled where the product will be loaded into. The next part is the loading phase where the holes are filled. Here the crew first 'baits' the holes by lowering a booster - a small cylindrical explosive - attached to a detonation cord into the hole, then the product is loaded into the hole and the hole is all topped off with stemming. The booster is attached to a detonation cord that sticks out of the top of the hole. The last step is to connect the cords according to the plan, before the shot is set off from a safe distance.

\section{OUR INVESTIGATION}


Our study was part of a larger a problem-orientated ethnography. However, in this paper, we only report on the orientation part of this study, as we use it as an example to reflect on how everyday work can be studied. For this, the first author visited blast crews and followed them around for multiple workdays in a row. The researcher had received basic training and done the necessary inductions to work in a blast crew, but had no prior experience in the field. If the management of the quarry or mine gave authorisation to work for the researcher, he would help the crews out during work. Otherwise, he would only observe, ask questions, and take notes. During the work, the crews were observed and short questions were asked. During breaks, the researcher did formal interviews with the crew members.

The observed blast crews varied in size between three to ten people. There was always at least one shotfirer that was in charge of the crew. Each crew had at least one truck operator and one bench hand that did extra work on the ground. During preparations and the baiting of the holes, there is only a loose team structure with few pre-delegated tasks. The holes during the observed work varied between 3 and 15 meters deep and the number of holes per shot varied from 50 to 350 .

An aim of our study was to investigate the possibilities of crew resource management training for blast crews in mining. Because of this, we were mostly interested in teamwork processes and the interactions between crew members and agents outside the team. During this fieldwork, the researcher observed surprisingly little explicit task related verbal communication. Yet, the crews seemed to be working efficiently and showed other teamwork processes such as mutual performance monitoring and back up behaviour (Salas 2005). Upon closer inspection, the researcher found that practitioners purposely left 'traces' for themselves and other crewmembers in the environment. A lot of communication was happening nonverbally, although not necessarily implicit.

Some of the practices were specific to teams, others were more universal. We do not know if these practices have evolved naturally or whether they had been designed (Hutchins 1991), but they did not come from the company's rules, procedures or formal training. These interactions were part of the process of how work gets done, but were not part of work-as-imagined by the blunt end, and we think they are unlikely to be found in an accident investigation. Therefore we see it as a good example of what everyday work investigations can find and how it will lead to different questions than accident investigations. We have chosen three of these interactions observed in one crew as examples to use in further reflection on how to shape further investigation.

\section{THE OBSERVED BLAST CREW INTERACTIONS}

\section{Hose placement as a beacon}

The truck with the product needs to move many times for the hose to reach all the holes. The number of times the truck is moved is kept as low as possible. This reduces the risk of damaging something with the truck and increases efficiency. When loading with a hose, a good new position for the truck allows the hose to reach as much unfilled holes as possible. To determine the best position for the truck in a new row of holes, the hose is detached from the truck and used to measure out the ideal location. The output end of hose is placed 
in the hole furthest away in the new row of holes. The part of the hose that connects to the truck is then placed as far back in the direction where the truck is coming from. The end of the hose that attaches to the truck is a beacon for the truck driver and spotter where to stop the truck.

\section{Using knots to indicate hole status}

If a hole is wet, there is water at the bottom of the hole. Some types of product can push any water out of the hole and this works best if the product is released below the water. Because of this, it is important the hose is dropped till the bottom of a hole. As the product gets released under the water, the water will be pushed out at the top of the hole.

When baiting the holes, crewmembers use different knots for wet and dry holes when they tie the detonation cord to the pole next to the hole. These knots signal to the hose operator that a hole is wet.

\section{Stone as a fault warning}

After baiting a hole, the booster should reach the bottom of the hole. It can happen that while lowering a booster into a hole, the booster gets blocked and will not go down by itself. It happens that the booster gets stuck in such a way that it cannot be pulled up either with a soft pull and this is when crewmembers need to be extra careful. Pulling too hard on the cord can cause the cord to snap, set off the booster and create an explosion. If a booster is stuck like this, the crewmember baiting puts a stone on top of the hole. The stone is a reminder to the crewmember at which hole this happened, a signal to other crewmembers something is wrong with the hole, as well as a blockade to anyone who wants to work with the hole.

\section{CONSIDERATIONS OF EVERYDAY WORK OBSERVATIONS}

Our observations generated a number of questions:

- "Are these actions good for safety?"

- "Are they desirable or necessary?"

- "Are there alternatives to these actions?"

- "Where did these actions come from, if not from the training or procedures? "

These are only some of the questions that can be asked, but they do show questions can go in different directions. Some questions are about understanding what is happening, some are about how to judge these actions, and others look for alternatives. Some questions look at the activity and team performing them, while other questions look for relations with other aspects. Depending on the view on safety and goals of the researchers some questions get more or less priority, and some questions might make no sense at all.

There are many differences between different schools of thought and some of the differences are very subtle. We have, however, aimed to capture the considerations that set 
different schools of thought on safety apart the most. By making these considerations explicit, we aim to help mould everyday work investigations into something practical.

\section{GOAL}

The first consideration - which will shape all other considerations - is the goal of the investigation. An investigation is either; 1 ) normative, when it tries find the best way of doing things or find where things are currently suboptimal, 2) descriptive, when the goal is to describe and understand what currently is happening, or 3) formative, when there is a search for new possibilities to do things.

\section{NORMATIVE APPROACH}

An investigation with a normative approach has the goal to prescribe how work should or should not be done, or how a system should or should not behave. In normative investigations observations are compared and can be benchmarked. This is either to find a norm, or work is compared to a predetermined norm. A normative question we could ask for our blast crews is "Are these practices good for safety?"

\section{Norm-finding}

In norm-finding normative investigations, the goal is to find the best way to do a job on one or multiple measures, which then are turned into instructions or constraints for the workers. The first task analyses from Taylor and Gilbreth did just this (Annett 2000). Instruction based approaches provide guidance for the workers what to do, should lead to workers do a task in the best known way, lead to less variability between workers and should prevent workers from making errors. In closed systems, where the context tends to be similar, this works well. In open systems it is difficult to say in advance what a worker should do, as the context changes more often, which makes it difficult to give a single set of instructions. An alternative for these systems the constraints-based approach. In a constraints-based approach the goal is not to tell the worker how the job should be done; the goal is tell what a worker cannot do. By only providing constraints, workers have freedom to manoeuvre and adapt to the circumstances as they see fit within those boundaries (Vicente 1999). For our blast crew study we could look for different practices from other crews and compare these practices to the examples we identified. If certain practices are linked to more desirable events, than these practices could be used as instructions for other crews. If a certain practice is linked to undesirable events, constraints could be considered against such practice.

An example of a norm-finding study in troubleshooting comes from Schaafstal, Schraagen, and Berlo (2000). The researchers were asked to assist the Royal Dutch Navy in improving the individual skill of weapon engineers in diagnosing and fixing equipment problems. The researchers began by searching for expert troubleshooting strategies - both in the literature, and by testing and observing technicians of varying ability. As typical for a normfinding study, the goal was to find one or more "best ways" to undertake troubleshooting, which could be shared from the experts to the entire cohort of weapon engineers. Based on their investigation, the researchers designed a new training course around functional understanding of systems and a systematic search for faults. Originally this training was tested as an add-on to the existing training for the technicians. However, when skills of the 
trainees improved in subsequent tests, an entire training program for the engineers was redesigned around the new ideas. This redesigned training course was shorter than the original training, but when the trainees from this course were tested, they solved more problems in less time per problem than those trained the original way.

Other examples of norm-finding studies include Sanda et al. (2014) about drilling activities in mining, Rasker, Post, and Schraagen (2000) with feedback styles in command and control centres, and Staszewski and Davison (2000) on mine detection strategies.

\section{Norm-comparison}

Norm comparison is about how a system performs compared to pre-set norms. This is a common element in safety management already, it includes audits and compliance monitoring, which are considered the standard practice (Hopkins 2007). However, when audits are used as a tool to change behaviour directly, rather than to learn about behaviour, they would not fall under our definition of everyday work investigations. With this approach, it is easy to make sense of what is observed and to determine what needs to be achieved. A norm comparison study highlights the current state in relation to a norm, but it is limited in that it tells nothing about the norm that is used. Even if it is well established that a certain way of doing a job is linked to fewer slips, it might have other undesired side effects, such as reduced fatiguing people more or being less resource efficient. Norm comparison studies are not sensitive to unintended consequences or possible good reasons why people deviate from a norm.

A 'soft' normative approach avoids judging whether the difference is good or bad. This approach builds upon theories made from accident investigations that very much tried to understand what everyday work was like before the accident. Both practical drift (Snook 2000) and normalisation of deviance (Vaughan 1999) see deviations from standard procedures as both inevitable and necessary. Investigation of work, not instigated by accidents, confirm that deviations and work arounds are often necessary (Kontogiannis and Malakis 2012). Over time however, deviations in multiple areas can interact with each other, as well as practices drifting beyond the boundary of safe operations. Therefore it is important for organisations to investigate their practices and reflect on whether they are safe (Dekker and Pruchnicki 2013).

Our initial observations of blast crews walked the line between descriptive and norm comparison. We aimed to capture what was going on, a more descriptive approach, but as we were surprised by what we found, we then started comparing it to norms in the form of procedures. This added norm-comparison elements. However, after finding no relevant link to procedures, continuing with a norm comparison approach would have been impossible. As there was no "norm" against which to compare. A common critique on many normative investigations is not necessarily that they are normative per se, but that they make unrealistic assumptions about human work. The way these models assume work should happen is often so different from how work actually happens, that these models lose their usefulness (Sheridan 2001). This critique applies more to instruction-based and normcomparison approaches than constraint-based and soft-normative approaches. 
An example of a norm-comparison study comes from Rodrigues et al. (2015). They looked whether safety climate affected safety performance and risk acceptance across multiple furniture companies. The study was norm-comparative in that it started with a preestablished checklist for safe conditions, behaviours and procedures. The goal was not to investigate or verify these norms but to find out what caused organisations to move towards or away from the norms - specifically, whether better safety climate correlated with closeness to the norms. A questionnaire was used to measure safety climate and risk acceptance. To measure safety performance an audit was used, which is a norm-comparison approach. They had a pre-established checklist with 112 items about on the conditions of the workplace, equipment and machinery, and safety behaviours and procedures. For the audit, the researchers rated organisations on each item from 1 to 5 for how well they were doing. The pre-established items show that the researchers already had an ideal picture of work. As a normative study, the study needs a way to compare and make sense out of the data. This study, like many quantitative studies, used a statistical test to look for correlations and to see whether random variation could explain the found differences. The test found that high safety climate was linked with high safety performance and low risk acceptance. From this, the researchers concluded that safety climate influences safety performance and risk acceptance, establishing high safety climate as an additional norm to strive for.

Other studies doing norm-comparision investigations include Rydenfält et al. (2013) with compliance to the WHO surgical safety checklists and Garnerin et al. (2008) compliance with protocol on patient identity.

\section{DESCRIPTIVE APPROACH}

In a descriptive study a researcher looks at how a job is done or how a system behaves and why, opposed to how it should behave. Descriptive investigations do not immediately provide clues on what to do, but can help reframe problems, help uncover interesting areas, or provide a general understanding, from which decisions can be made. In our example of blast crews, the investigation in which we identified the practices was descriptive. Without this we could not explain what was happening. Follow up questions such as 'where do these practices come from?' fit with a descriptive approach. A field that advocated a more descriptive approach is naturalistic decision making (NDM) (G. A. Klein 1998; Orasanu and Connolly 1993). NDM was interested in describing the process with which people made decisions (Nemeth and Klein 2010). In the US descriptive approaches to work became popular with NDM and distributed cognition, while in Europe descriptive studies on work had been around longer (Rasmussen and Jensen 1974; de Keyser and Piette 1970). A limitation of descriptive studies is that they only look at the current ways of doing things, and do not explore other possibilities. Descriptive studies do not examine how an intervention would effect the described processes (Woods and Dekker 2000). It can also lead a descriptive study to focus on a 'workaround', while with a small change this workaround would not be needed at all (Vicente 1999). The lack of focus on a solution means the results can be applicable to wide set of decisions, but can make it difficult to translate it into concrete interventions.

Carvalho et al. (2006) provide an example of a descriptive study, with their investigation of cultural and cognitive issues of nuclear power plant operations. They applied an 
ethnographic approach, using observations during work and simulations, and post-event interviews with control room operators. The study provides in-depth descriptions of how crews interact with each other and with technology, and how they deal with certain events. From there, the researchers focus on particular issues such how distractions affect operators and in turn how the operators deal with distractions. Whilst the researchers do ultimately make suggestions for improvement based on their results, improvement is not the focus of the study and did not guide the research design.

Other examples of descriptive studies include Carim et al. (2016) on how pilots use procedures in non-normal situations, Schraagen (2011) on coordination and communication in medical team during non-routine situations, and Vicente, Mumaw, and Roth (2004) on nuclear power operators during normal operations.

\section{FORMATIVE APPROACH}

When taking a formative approach the goal is to find new ways of doing things. Vicente (1999) defined a formative approach as "Based on identifying requirements that must be satisfied so that a system can behave in a new, but still desired, way". Knowing more ways of doing things increases the flexibility of the system (Vicente 1999) and can be a useful goal in itself. While many research projects have the end goal to find a new and better way of doing things, there are few methods that are formative. Cognitive Work Analysis (Vicente 1999) and ethnography (Dekker, Nyce, and Hoffman 2003) have been suggested to be able to fulfil this role, by looking at what a system does and why it does what it does. By understanding the goals and constraints that influence a system, alternatives can be sought that fit with these goals and constraints. However these methods do not have a structured process or step-by-step guides. Theoretically Cognitive Work Analysis has clean structured process with analyses on multiple levels. However, in practice the methodology is often messy and analyses on one level find results for another level (Vicente 1999).

A detailed example of an entire formative analysis comes from Jatobá et al. (2016). In this study, the researchers aimed to understand and improve patient risk assessment process used for prioritising patients. Their main question was "How can work situations be enhanced and support devices be designed in order to improve the risk assessment process in primary health care?". The study does build a somewhat descriptive understanding of what is currently done, but the description is in support of finding new ways it is not a goal in itself. The formative intent influenced the way the study was conducted from the very first step. Jatobá et al. began by 'framing' the entire study, to understand what the managers and workers wanted to improve and sought to achieve with the improvement process. Next, they used observations and interviews to evaluate various features of the workplace. From there, they then observed and modelled the work processes, identifying specific problems and opportunities for improvement. The study did not compare the work pre-established model like a normative investigation would. Unlike a purely descriptive study, Jatobá et al. constantly engaged on what was imperfect and could be improved.

Not all formative investigations need to be as elaborate and formative from the beginning. With our blast crews, a question such as "Are there ways other than the observed ways of doing things?" falls into the category of formative studies. Cornelissen et al. (2012) and 
Hassall and Sanderson (2014) describe methods to search for alternative ways work can be done. Both start with an investigation into the existing domain, goals, constraints and strategies that make up work. The step where investigation into strategies becomes formative is where they differ. Cornelissen et al. (2012) tries to link existing actions to different parts of the system, to find new combinations of goals and strategies. If we apply this to our blast crews, we could look into whether objects other than hoses could be used as beacon. For our blast crews using hoses as a beacon, using this method, we can think of alternative strategies to determine where to park the loading truck, like 'intuitive' strategies where crew members use a 'fingerspitzengef€ uhl', or crews that use an 'analytical' strategy, and calculate a good position for the truck based on the number of holes, the distance between the holes and hose length. Both the method of Cornelissen et al. (2012) and Hassall \& Sanderson (2014) are formative in that they are systematic and go beyond describing how things are, and look for other possibilities.

Formative investigations are successful when they find new ways of doing things that work, but it is difficult to know how valid or complete an investigation is. The results cannot be compared to anything. A quick-and-dirty formative study might find many options that only later shown to be poor alternatives, while a thorough study might fail suggest any changes that it considers desirable. No matter which formative method is used, no kind of analysis can find all possible ways of doing things(Cornelissen et al. 2014).

\section{DISCUSSION}

The lines between the goals above can become blurry. Studies that set out to be normative can expose new ways in which people are doing things. Descriptive studies are often part of a larger project with normative or formative goals. Even if it is not part of a larger project, descriptive studies often suggest how a system can be changed for the better. Formative studies often rely on descriptive and normative methods.

\section{POST-POSITIVIST VS. SOCIAL CONSTRUCTIVIST VIEW}

For any investigation of everyday work there is the question about how we view knowledge about safety. In a post positivist worldview we want to know about something that exists in an objective world outside of people's subjective perception (as applied by, for example, Normal Accident Theory, the Swiss Cheese Model and Behaviour Based Safety). If safety is approached in a post positivist way, it is either something a system has or something it does. Definitions of safety as "freedom from unacceptable risks" (Lowrance 1976) suggest that safety reflects something that exists in an objective world. The line between acceptable and unacceptable might be subjective, but the risks and freedom from it exist in the world. Investigations with a normative goal tend to have a post positivist view of safety. They believe there is something that can be done better. One can still recognise that safety means different things to different people, but this is then a matter of semantics. There is an underlying objective goal to be reached by improving safety, which is free from subjective perception. In safety this is usually related to decreasing the number of accidents, damages, fatalities or injuries.

Another social constructivist view, in contrast, considers what and how meaning is given to something by people. Studies that take this approach tend to be descriptive. The early High 
Reliability Theory studies are an example (Rochlin 1999). The researchers found that safe operations did not just mean not having accidents for practitioners; it was about what was done to prevent accidents. This was a lot more than avoiding errors; this also included being critical of current operations, learning from near misses and looking ahead to what might happen in the future. This changes which activities relate to safety and how safety can be improved. To relate this to our blast crew observations, it raises the question what value crewmembers see in the actions we observed. What part do these activities play in their view and what value is assigned to them? The crews might not only see the knots as communicating information about the hole, but also as a way to stay mindful, to use a High Reliability Theory concept. Mindfulness in turn can be an important piece in how reliability or safety is created (Weick, Sutcliffe, and Obstfeld 1999).

There are more worldviews than positivism and constructivism, but most fall on a spectrum between these two. Resilience Engineering, for example, has both been used from a postpositivist perspective and social constructivist perspective (Le Coze and Pettersen 2008). Positivism has the advantage that it is easier to combine with hard sciences, as they are often rooted in a positivist worldview, and the studies often provide clear goals to aim for. It can be harder to combine with the understanding of multiple diverse individuals and the concepts the study uses can function as a lens that make it blind to things that do not find within these concepts. Constructivism is more sensitive to diverse human viewpoints and the study of things that are difficult to define in advance, but as it lacks a universal vision of truth or good, it can be difficult to translate in interventions.

\section{LEVEL AND UNITS OF ANALYSIS}

The level of analysis refers to the scope of what is investigated: how micro or macro the orientation of a study is. What is significant at one level of analysis is not necessary so at another level of analysis. A study can look at multiple levels of analysis, this, however, comes with extra challenges (K. J. Klein and Kozlowski 2000). Most schools of thought in safety do not deny the relevance of different levels of analysis in general, but can place more focus on some levels, or give their advice on a specific level. Normal Accident Theory and High reliability Theory both place the emphasis on the organisational level, but do not rule out that the actions of individuals matter. In the High Reliability Theory literature, the actions of one individual are described, but the meaning that is given to these actions is about how this fits into the organisational processes (Weick, Sutcliffe, and Obstfeld 1999). The latent failure model says actions on the individual level always play a role, but looks how other levels influence these actions. Resilience Engineering can be applied at different levels and across multiple levels, as it sees differences in goals across levels as a reason systems can fail (Woods and Branlat 2011).

Unit of analysis is about the type of things an investigation looks at. Safety research often used accidents as a starting point, but everyday work analysis moves away from this. One way adjust is to rely on what accident models describe as relevant. Normal Accident Theory would tell investigations to focus on qualities or features of an organisation. Heinreich's accident pyramid would guide you towards incidents and unsafe acts, which returns in behaviour based safety (Krause 1997). The latent failure model would talk about barriers and holes in them. However, applying these concepts to everyday working, without the 
hindsight of an accident, can be challenging. The schools of thought that focus more on everyday work provide easier to apply concepts. High Reliability Theory looks at the processes with which people organise in risky fields (La Porte and Consolini 1991). Resilience Engineering often looks at what it takes to succeed in varying conditions and with that often ends up looking at adaptation (Hollnagel, Woods, and Leveson 2006). Even in fields that study people at work, there are still (subtle) differences. For example, Naturalistic Decision Making and Cognitive Systems engineering both look at people at work and could design a similar study. However Naturalistic Decision Making tries to analyse how people make decisions, and the models it produces are about what happens (mostly) inside their head, while cognitive systems engineering leans more towards analysing what happens at the intersection between people, technology, and work, leaving it more of a black box of what happens inside the head of people (Hoffman and Militello 2008; Hollnagel and Woods 2005). Studies of everyday work have often proven to be useful for the improvement of safety, but it is not a given that they can be used for safety. Overall, this shows the challenge of finding relevant unit of analysis for investigations of everyday work.

In our investigation with blast crews we started looking at the team level and interactions between team members, simply because it was the most obvious way in which work got done and aligned with the exploration of possibilities for crew resource management training. If we ask the question "where did these practices come from?" we are likely to look at other levels of analysis, such as the influences of individuals or organisational features. If we have hypotheses on what form these practices, such as mine policies regarding stones on benches, we could do a normative study and test whether these practices are more likely to develop in the hypothesised conditions. If we have no hypotheses, we are more likely to take a descriptive approach and find how a practice comes to be. Levels of analysis do not only apply for the units of analysis are systems or objects. Research that focuses on actions, like organisational routines, treats actions as subsets of other actions. Interviewing is an activity that is nested within the activity of hiring a person (Pentland and Hærem 2015).

In most investigations the unit of observation is close to the unit of analysis. If the goal is to know about whether people wear personal protective equipment (PPE), the investigation will probably look at people wearing their PPE in a number of situations. However, many units of analysis are infeasible or impossible to observe directly. The tidiness of a site, for example, is observable, but it can be assessed in different ways. Even when people agree on its definition, there are different ways to operationalize it. One can investigate what tools are not in their predefined place at the end of the day, how long it takes before tools are found, or count objects in an area that are not supposed to be there. The unit of observation is about how the unit of analysis is operationalized, which includes both objects being looked at and when it is being looked at.

In practice, there are usually multiple units of analysis and each unit of analysis can have multiple units of observations. For work design, Carayon et al. (2007) suggest the units of analysis the organisation, the tools, the environment, the tasks and the individuals, as a starting point for work design to improve patient safety. The units of analysis go across multiple levels of analysis and for each unit of analysis they list multiple analysis techniques that come with different units of observation. 


\section{CONCLUSION}

In this paper we have used our empirical observations of blast crews to both inform practical steps for doing everyday work investigations with a focus on safety, and reflect on their meaning vis-à-vis various schools of thought.

In the different choices there is a tension between 'for safety', the prevention of specific special events, and the 'everyday', something unspecific and ubiquitous. A normative and positivist approach, that uses units of analysis based on existing theory, is theoretically clearly relevant for safety. However, it is prone to preconceptions that poorly fit with everyday work that is being investigated. This hampers learning potential. A descriptive and constructivist approach offers more possibility to investigate everyday work and to learn things that are unlikely to be discovered through a normative, accident-prevention focussed approach. However, the link between the research and 'for safety' is more indirect. It will often be harder to translate the findings into interventions.

For this reason, there is a trend for safety-motivated everyday work research to reduce emphasis on safety as an end-goal. Safety-II focusing on what helps create success, and recognises that not everything investigated will turn out be relevant for safety. (Hollnagel 2014). Both Resilience Engineering and High Reliability Theory do not talk about safety, but rather 'resilience' and 'reliability'. These terms are safety-adjacent, and but they are not same as safety. At best they consider safety as one consideration in determining whether a successful outcome is achieved (Morel et al. 2008; Leveson 2011; Weick 1987). The shift from 'safety' to 'success' means that everyday work investigations may be inappropriate for considering hazards that do not get in the way of short-term success. For example a worker may experience long-term harm (such as from asbestos) but may appear to be working successfully.

By reflecting on research practice, we have uncovered and discussed assumptions that are shaping everyday work investigations. Critical consideration of these assumptions will allow practitioners and researchers to conduct everyday work investigations that open up access to new knowledge whilst retaining relevance for safety.

\section{ACKNOWLEDGEMENTS}

\section{REFERENCES:}

Annett, John. 2000. "Theoretical and Pragmatic Influences on Task Analysis Methods." In Cognitive Task Analysis, edited by Jan Maarten Schraagen, Susan Chipman, and Valerie Shalin, 25-37. Mahwah, NJ: Lawrence Erlbaum Associates.

Carayon, P., C. J. Alvarado, and A. Schoofs Hundt. 2007. "Work Design and Patient Safety." Theoretical Issues in Ergonomics Science 8 (5): 395-428. doi:10.1080/14639220701193157.

Carim, Guido C., Tarcisio Abreu Saurin, Jop Havinga, Andrew Rae, Sidney W. A. Dekker, and 
Éder Henriqson. 2016. “Using a Procedure Doesn't Mean Following It: A Cognitive Systems Approach to How a Cockpit Manages Emergencies." Safety Science 89. Elsevier Ltd: 147-157. doi:10.1016/j.ssci.2016.06.008.

Carvalho, Paulo V. R., Isaac L. dos Santos, and Mario C. R. Vidal. 2006. "Safety Implications of Cultural and Cognitive Issues in Nuclear Power Plant Operation." Applied Ergonomics 37: 211-223. doi:10.1016/j.apergo.2005.03.004.

Cook, Richard I., and David D. Woods. 1994. "Operating at the Sharp End: The Complexity of Human Error." In Human Error in Medicine, edited by Marilyn Sue Bogner, 255-310. Hillsdale, NJ: Lawrence Erlbaum Associates.

Cornelissen, Miranda, Roderick McClure, Paul M. Salmon, and Neville A. Stanton. 2014. "Validating the Strategies Analysis Diagram: Assessing the Reliability and Validity of a Formative Method." Applied Ergonomics 45 (6). Elsevier Ltd: 1484-1494. doi:10.1016/j.apergo.2014.04.010.

Cornelissen, Miranda, Paul M. Salmon, Daniel P. Jenkins, and Michael G. Lenné. 2012. "A Structured Approach to the Strategies Analysis Phase of Cognitive Work Analysis." Theoretical Issues in Ergonomics Science 14 (6): 546-564. doi:10.1080/1463922X.2012.668973.

de Keyser, V., and A. Piette. 1970. "ANALYSE DE L'ACTIVITÉ DES OPÉRATEURS AU TABLEAU SYNOPTIQUE D'UNE CHAINE D'AGGLOMÉRATION." Le Travail Humain 33 (3): 341-352.

Debono, Deborah S., David Greenfield, Joanne F. Travaglia, Janet C. Long, Deborah Black, Julie Johnson, and Jeffrey Braithwaite. 2013. "Nurses' Workarounds in Acute Healthcare Settings: A Scoping Review." BMC Health Services Research 13: 175. doi:10.1186/1472-6963-13-175.

Dekker, Sidney W. A. 2003. "Failure to Adapt or Adaptations That Fail: Contrasting Models on Procedures and Safety." Applied Ergonomics 34 (3): 233-238. doi:10.1016/S00036870(03)00031-0.

Dekker, Sidney W. A. 2005. "Past the Edge of Chaos." Human Factors and Aerospace Safety 5 (3): 267-278.

Dekker, Sidney W. A. 2014. The Field Guide to Understanding "Human Error." Farnham, UK: Ashgate publishing Co.

Dekker, Sidney W. A., James M. Nyce, and Robert R. Hoffman. 2003. "From Contextual Inquiry to Designable Futures: What Do We Need to Get There?" IEEE Intelligent Systems 18 (2): 74-77. doi:10.1109/MIS.2003.1193660.

Dekker, Sidney W. A., and Shawn Pruchnicki. 2013. "Drifting into Failure: Theorising the Dynamics of Disaster Incubation." Theoretical Issues in Ergonomics Science 15 (6): 534544. doi:10.1080/1463922X.2013.856495.

Garnerin, P., M. Arès, A. Huchet, and F. Clergue. 2008. "Verifying Patient Identity and Site of Surgery: Improving Compliance with Protocol by Audit and Feedback." Quality \& Safety in Health Care 17: 454-458. doi:10.1136/qshc.2007.022301.

Hassall, Maureen E., and Penelope M. Sanderson. 2014. "A Formative Approach to the Strategies Analysis Phase of Cognitive Work Analysis." Theoretical Issues in Ergonomics Science 15 (3): 215-261. doi:10.1080/1463922X.2012.725781.

Hoffman, Robert R., and Laura G Militello. 2008. Perspectives on Cognitive Task Analysis: Historical Origins and Modern Communities of Practice. Boca Raton: CRC Press.

Hollnagel, Erik. 2012. "Resilience Engineering and the Systemic View of Safety at Work: Why Work-as-Done Is Not the Same as Work-as-Imagined." In Kongress Des Gesellschaft Für 
Arbeitswissenschaft Vom 22 Bis 24 Februar 2012, 19-24. Dortmund: GfA-Press.

Hollnagel, Erik. 2014. Safety-I and Safety-II: The Past and Future of Safety Management. Farnham: Ashgate publishing.

Hollnagel, Erik, and David D. Woods. 2005. Joint Cognitive Systems: Foundations of Cognitive Systems Engineering. Boca Raton, FL, USA: CRC Press.

Hollnagel, Erik, David D. Woods, and Nancy Leveson, eds. 2006. Resilience Engineering: Concepts and Precepts. Farnham: Ashgate.

Hopkins, Andrew. 2007. "Beyond Compliance Monitoring: New Strategies for Safety Regulators." Law and Policy 29 (2): 210-225. doi:10.1111/j.1467-9930.2007.00253.x.

Hutchins, Edwin. 1991. “Organizing Work by Adaptation.” Organization Science 2 (1): 14-39. doi:10.1287/orsc.2.1.14.

Hutchins, Edwin. 1995. Cognition in the Wild. Cambridge, MA, USA: MIT Press.

Jatobá, Alessandro, Hugo Cesar Bellas, Renato Bonfatti, Catherine M. Burns, Mario Cesar R. Vidal, and Paulo V. R. Carvalho. 2016. "Designing for Patient Risk Assessment in Primary Health Care: A Case Study for Ergonomic Work Analysis." Cognition, Technology, and Work 18: 215-231. doi:10.1007/s10111-015-0355-x.

Klein, Gary A. 1998. Sources of Power: How People Make Decisions. Cambridge, MA, USA: MIT Press.

Klein, K. J., and Steve W. J. Kozlowski. 2000. "From Micro to Meso: Critical Steps in Conceptualizing and Conducting Multilevel Research." Organizational Research Methods 3 (3): 211-236. doi:10.1177/109442810033001.

Kontogiannis, Tom, and Stathis Malakis. 2012. "Remaining Safe by Working at the Edge of Compliance and Adaptation: Reflective Practices in Aviation and Air Traffic Control." Theoretical Issues in Ergonomics Science 14 (6): 565-591. doi:10.1080/1463922X.2012.672597.

Krause, Thomas R. 1997. The Behavior-Based Safety Process: Managing Involvement for an Injury-Free Culture. 2nd ed. New York, NY, USA: Van Nostrand Reinhold.

La Porte, Todd R., and Paula M. Consolini. 1991. "Working in Practice But Not in Theory: Theoretical Challenges of 'High-Reliability Organizations.'” Journal of Public Administration Research and ... 1: 19-47. http://www.jstor.org/stable/1181764.

Le Coze, Jean-Christophe, and Kenneth Pettersen. 2008. "Is Resilience Engineering Realist or Constructivist?" In 3rd Symposium on Resilience Engineering, edited by Erik Hollnagel, Francois Pieri, and Eric Riguad, 175-184. Juan-les-Pins, France: Ecole des Mines de Paris.

Leplat, Jacques, and Jean-Michel Hoc. 1983. "Tache et Activite Dans l'Analyse Psyholoique Des Situations." Cahiers de Psychologie Cognitive 3 (1): 49-63.

Leveson, Nancy G. 2011. Engineering a Safer World: Systems Thinking Applied to Safety. Edited by Joel Moses, Richard Neufville de, Manuel Heitor, Granger Morgan, Elisabeth Paté-Cornell, and William Rouse. Vasa. Cambridge, MA, USA: The MIT Press.

Lowrance, William W. 1976. Of Acceptable Risk: Sciene and the Determination of Safety. Los Altos, CA, USA: William Kaufmann.

Merry, A. F., and A McCall Smith. 2001. Errors, Medicine and the Law. Cambridge: cambridge university press.

Morel, Gaël, René Amalberti, Christine Chauvin, Gaël Mörel, René Amalberti, and Christine Chauvin. 2008. "Articulating the Differences between Safety and Resilience: The 
Decision-Making Process of Professional Sea-Fishing Skippers." Human Factors 50 (1): 1-16. doi:10.1518/001872008X250683.

Nemeth, Christopher P., Richard I. Cook, and David D. Woods. 2004. "The Messy Details: Insights from the Study of Technical Work in Healthcare." IEEE Transactions on Systems, Man, and Cybernetics Part A:Systems and Humans. 34 (6): 689-692. doi:10.1109/TSMCA.2004.836802.

Nemeth, Christopher P., and Gary A. Klein. 2010. "The Naturalistic Decision Making Perspective." In Wiley Encyclopedia of Operations Research and Management Science. doi:10.1002/9780470400531.eorms0410.

Orasanu, Judith M., and Terry Connolly. 1993. "The Reinvention of Decision Making." In Decision Making in Action: Models and Methods, edited by Gary A. Klein, Judith Orasanu, Roberta Calderwood, and Caroline E. Zsambok, 3-20. Norwood, NJ: Ablex.

Pentland, Brian T., and Thorvald Hærem. 2015. "Organizational Routines as Patterns of Action: Implications for Organizational Behavior." Annual Review of Organizational Psychology and Organizational Behavior 2 (1): 465-487. doi:10.1146/annurevorgpsych-032414-111412.

Rasker, P. C., W. M. Post, and Jan Maarten Schraagen. 2000. "Effects of Two Types of IntraTeam Feedback on Developing a Shared Mental Model in Command \& Control Teams." Ergonomics 43 (8): 1167-1189. doi:10.1080/00140130050084932.

Rasmussen, J., and A. Jensen. 1974. "Mental Procedures in Real-Life Tasks: A Case Study of Electronic Trouble Shooting." Ergonomics 17 (3): 293-307. doi:10.1080/00140137408931355.

Reason, James. 1997. Managing the Risks of Organizational Accidents. Aldershot, UK: Ashgate publishing Co.

Rochlin, Gene I. 1999. "Safe Operation as a Social Construct." Ergonomics 42 (11): 15491560. doi:10.1080/001401399184884.

Rodrigues, M. A., P. M. Arezes, and C. P. Leão. 2015. "Safety Climate and Its Relationship with Furniture Companies ' Safety Performance and Workers' Risk Acceptance." Theoretical Issues in Ergonomics Science 16 (4): 412-428. doi:10.1080/1463922X.2014.1003991.

Rydenfält, Christofer, Gerd Johansson, Per Odenrick, Kristina Åkerman, and Per Anders Larsson. 2013. "Compliance with the WHO Surgical Safety Checklist: Deviations and Possible Improvements." International Journal for Quality in Health Care 25 (2): 182187. doi:10.1093/intqhc/mzt004.

Salas, Eduardo. 2005. “Is There a 'Big Five' in Teamwork?” Small Group Research 36 (5): 555599. doi:10.1177/1046496405277134.

Sanda, Mohammed-Aminu, Jan Johansson, Bo Johansson, and Lena Abrahamsson. 2014. "Using Systemic Structural Activity Approach in Identifying Strategies Enhancing Human Performance in Mining Production Drilling Activity." Theoretical Issues in Ergonomics Science 15 (3): 262-282. doi:10.1080/1463922X.2012.705916.

Schaafstal, A., Jan Maarten Schraagen, and M. van Berlo. 2000. "Cognitive Task Analysis and Innovation of Training: The Case of Structured Troubleshooting." Human Factors 42 (1): 75-86. doi:10.1518/001872000779656570.

Schraagen, Jan Maarten. 2011. "Dealing with Unforeseen Complexity in the OR: The Role of Heedful Interrelating in Medical Teams." Theoretical Issues in Ergonomics Science 12 (3): 256-272. doi:10.1080/1464536X.2011.564481. 
Sheridan, Thomas B. 2001. "Rumination on Automation, 1998." Annual Reviews in Control 25: 89-97. doi:10.1016/S1367-5788(02)00009-8.

Snook, Scott A. 2000. Friendly Fire: The Accidental Shootdown of U.S. Black Hawks over Northern Iraq. Princeton, NJ: Princeton University Press.

Spear, Steven J., and Mark Schmidhofer. 2005. "Ambiguity and Workarounds as Contributors to Medical Error." Annals of Internal Medicine 142 (8): 627-630.

Staszewski, James J, and Alan D. Davison. 2000. "Mine Detection Training Based on Expert Skill." In Detection and Remediation Technologies for Mines and Mine-like Targets V, Proceedings of Society of Photo-Optical Instrumentation Engineers 14th Annual Meeting, edited by A. C. Dubey, J. F. Harvey, J. T. Broach, and R. E. Dugan, 90-101. doi:10.1117/12.396203.

Taylor, Frederick Winslow. 1911. The Principles of Scientific Management. New York, NY, USA: Harper \& Brothers. http://books.google.co.uk/books?id=tw-YGBovG8kC.

Vaughan, Diane. 1999. "THE DARK SIDE OF ORGANIZATIONS: Mistake, Misconduct, and Disaster." Annual Review of Sociology 25 (1): 271-305. doi:10.1146/annurev.soc.25.1.271.

Vicente, Kim J. 1999. Cognitive Work Analysis. London: Lawrence Erlbaum Associates.

Vicente, Kim J., Randall J. Mumaw, and Emilie M. Roth. 2004. "Operator Monitoring in a Complex Dynamic Work Environment: A Qualitative Cognitive Model Based on Field Observations." Theoretical Issues in Ergonomics Science 5 (5): 359-384. doi:10.1080/14039220412331298929.

Weick, Karl E. 1987. "Organizational Culture as a Source of High-Reliability." California Management Review 29 (2): 112-127.

Weick, Karl E., Kathleen M. Sutcliffe, and David Obstfeld. 1999. “Organizing for High Reliability." Research in Organizational Behavior 21: 81-123. doi:10.4135/9781452229805.n175.

Woods, David D., and Matthieu Branlat. 2011. "Basic Patterns in How Adaptive Systems Fail." In Resilience Engineering in Practice: A Guidebook, 127-144.

Woods, David D., and Sidney W. A. Dekker. 2000. "Anticipating the Effects of Technological Change: A New Era of Dynamics for Human Factors." Theoretical Issues in Ergonomics Science 1 (3): 272-282. doi:10.1080/14639220110037452.

Woods, David D., Sidney W. A. Dekker, Richard I. Cook, Leila Johannesen, and Nadine Sarter. 2010. Behind Human Error. 2nd ed. Farnham: Ashgate Publishing limited. 